\title{
A somatization comorbidity phenotype impacts response to therapy in rheumatoid arthritis: post-hoc results from the certolizumab pegol phase 4 PREDICT trial
}

Jeffrey R. Curtis ${ }^{1 *}$, Christopher Herrem², 'Matladi N. Ndlovu' ${ }^{3}$, Cathy O'Brien ${ }^{3}$ and Yusuf Yazici ${ }^{4}$

\begin{abstract}
Background: Comorbidities may contribute to disease activity and treatment response in rheumatoid arthritis (RA) patients. We defined a somatization comorbidity phenotype (SCP) and examined its influence on response to certolizumab pegol (CZP) using data from the PREDICT trial.

Methods: Patients in PREDICT were randomized to the patient-reported Routine Assessment of Patient Index Data 3 (RAPID3) or physician-based Clinical Disease Activity Index (CDAl) for treatment response assessment. Post-hoc analyses identified patients with the SCP, which included diagnosis of depression, fibromyalgia/myalgias, and/or use of medications indicated for treatment of depression, anxiety, or neuropathic pain. The effect of the SCP on RAPID3 or CDAl response at week 12 and low disease activity (LDA; Disease Activity Score in 28 joints based on erythrocyte sedimentation rate $\leq 3.2$ ) at week 52 , in week-12 responders, was analyzed using non-parametric analysis of covariance (ANCOVA).

Results: At baseline, 43\% (313/733) of patients met the SCP classification. Patients with the SCP were 9\% more likely to withdraw from the trial. American College of Rheumatology 20\% (ACR20), ACR50, and ACR70 responses were $5-14 \%$ lower among those with the SCP, and 11\% more patients reported adverse events (AES). Patients without SCP in the CDAl arm were twice as likely to achieve LDA at week 52 compared with those with SCP (32\% versus 16\%). No differentiation by SCP was observed in the RAPID3 arm (pooled result 21.5\%).

Conclusions: We operationalized a potentially important somatization comorbidity phenotype in a trial setting that was associated with a substantially lower likelihood of treatment response and a higher frequency of AEs. Including large numbers of patients with this phenotype in RA trials may reduce the measured clinical effectiveness of a new molecule.
\end{abstract}

Trial registration: ClinicalTrials.gov, NCT01255761. Registered on 6 December 2010.

Keywords: Rheumatoid arthritis, Disease activity, Patient-reported outcomes, Comorbidities, Depression, Anxiety, Fibromyalgia, RAPID3, CDAI

\footnotetext{
*Correspondence: jrcurtis@uabmc.edu

'Division of Clinical Immunology and Rheumatology, University of Alabama

at Birmingham, FOT 802, 510 20th Street South, Birmingham, AL 35294, USA

Full list of author information is available at the end of the article
} 


\section{Background}

Comorbidities have been shown to substantially contribute to disease activity and treatment response in rheumatoid arthritis (RA) and should therefore be considered when devising treatment strategies for patients with RA [1-4]. Anxiety and depression are more common in people with RA than in the general population [5], and depression, fatigue, and fibromyalgia have been associated with increased disease activity, reduced odds for reaching clinical remission in $\mathrm{RA}$, and reduced treatment effects and quality of life [4-8]. However, the impact of these comorbidities on the magnitude of response in a clinical trial setting has not been well characterized, and an efficient approach to identifying patients with these conditions within an RA trial program has not been previously well-described.

Clinical assessment tools, such as the Disease Activity Score in 28 joints (DAS28) and Clinical Disease Activity Index (CDAI), and patient-reported outcomeonly tools, such as the Routine Assessment of Patient Index Data 3 (RAPID3), have proven effective for evaluating RA disease activity and predicting treatment response to guide patient management in RA [9-11]. The presence of comorbidities may also influence treatment outcomes indirectly due to the varying definitions of the state of remission or low disease activity (LDA) across different assessment tools [12]. There is currently no universal agreement on the best measurement tool for RA disease activity, given the strengths and limitations of each [9, 12-14].

The goal of these exploratory, post-hoc analyses was to define a "somatization comorbidity phenotype" (SCP) that could classify patients with RA participating in a clinical trial who had one or more conditions (e.g. fibromyalgia) that might have contributed to chronic pain independent of RA disease activity, or who had conditions (e.g. depression) other than RA that could have influenced pain and the patient's self-management of their condition. The second aim was to evaluate whether this phenotype influenced treatment response as assessed by the CDAI and RAPID3 tools and more traditional measures (e.g. ACR response). The analysis was conducted in the Patient/Physician Reported Efficacy Determination in Clinical Practice (PREDICT) trial, among patients with moderate to severe RA initiating treatment with the antitumor necrosis factor (anti-TNF) agent, certolizumab pegol (CZP).

\section{Methods}

\section{Study design}

The PREDICT trial (NCT01255761) was a randomized, phase 4 trial that examined the predictability of CZP treatment success at week 52 based on treatment response at week 12, as assessed by the patient-reported
RAPID3 or the mostly physician-based CDAI in patients with RA with moderate to severe, active disease. The primary hypotheses tested were whether the RAPID3 was comparable to the CDAI tool in assessing response to CZP therapy at week 12, and evaluating the positive predictive value of this classification against the RA disease state at week 52. Detailed methods and the primary results of the PREDICT study have been published previously [15].

In brief, patients aged $\geq 18$ years, with a diagnosis of adult-onset RA for $>3$ months' duration at baseline were eligible for this 52-week study. RA was diagnosed according to the American College of Rheumatology (ACR) 1987 classification criteria [16]. Patients were also required to have an unsatisfactory response or intolerance to $\geq 1$ disease-modifying antirheumatic drug (DMARD). Patients with fibromyalgia requiring treatment were excluded from the study as per protocol. The purpose of this exclusion was to remove patients who were hypothesized to have an attenuated treatment response as measured by the two tools (i.e. RAPID3 and CDAI) used in the trial, as both contain a patient measurement component. This exclusion was similar to a general exclusion in many RA trials where investigators are requested to exclude patients who have concomitant medical conditions that might interfere with the interpretation of the study results [17-19]. The exclusion was implemented by each local site investigator; no systematic identification or exclusion at the time of randomization was enforced.

Both RAPID3 and CDAI assessments were performed on all patients throughout the study at each visit. Patients were randomized 1:1 to protocolized management based upon either the RAPID3 or CDAI, and patients remained blinded throughout the study to their randomized group. Randomization was performed through an interactive voice/web-based response system (IXRS). All patients received a loading dose of CZP (400 mg at weeks 0, 2, and 4), followed by CZP $200 \mathrm{mg}$ every second week (Q2W) until week 50.

At week 12, all patients were classified as responders or non-responders according to their randomized assessment group. RAPID3 response was defined as $\leq 6$ (LDA) or $\geq 20 \%$ improvement from baseline, and CDAI response was defined as $\leq 10$ (LDA) or $\geq 20 \%$ improvement from baseline. These cutoffs for CDAI and RAPID3 response were established in the PREDICT study protocol prior to published reports of a minimal clinically important difference (MCID) for CDAI [20] and RAPID3 [21]. All patients who were not week-12 RAPID3 or CDAI responders, or were withdrawn prior to week 12, were classified as non-responders. The nonresponders included a subset of patients who had no improvement by week 12 ("week-12 failures"; those with no RAPID3 improvement or $<1$ point CDAI improvement, 
based on the assessment group to which they were randomized), and were withdrawn from the study and CZP treatment. All other non-responders who were not week-12 failures continued treatment with CZP $200 \mathrm{mg}$ Q2W, unless they reached a high disease activity state (CDAI $>22$ or RAPID3 >12) [22] at two consecutive visits, at which point they were withdrawn from the study.

\section{Somatization comorbidity phenotype}

The somatization comorbidity phenotype (SCP) was defined post hoc to the trial, but a priori to conducting these analyses. Based on clinical interest and suggestions from observational data that fibromyalgia, depression, anxiety, psychological distress and similar conditions might influence RA assessment [17, 23-26], we hypothesized that patients with this phenotype might have a suboptimal treatment response in an RA clinical trial. The phenotype was operationally defined by use of concomitant medications indicated for the treatment of depression, anxiety, or neuropathic pain (i.e. selective serotonin reuptake inhibitors (SSRIs), duloxetine, venlafaxine, milnacipran, pregabalin, gabapentin, amitriptyline, tizanidine, cyclobenzaprine, methocarbamol, or metaxalone), or ongoing baseline medical diagnosis of depression, chronic pain, fibromyalgia, or myalgias (classified using the Medical Dictionary for Regulatory Activities (MedDRA) version 15.1 with the terms: cervical tension myalgia, generalized muscle pain; muscle pain; muscle pain hip area; myalgia; and myalgias). Information classifying patients by SCP status was taken from the medical history and concomitant medication data taken at the beginning of the study. Data on the duration of medical diagnoses were not collected, therefore there was no requirement for the use of these concomitant medications or diagnoses to be of a chronic nature. A diagnosis of insomnia and use of narcotics was not included in the SCP definition, given that RA-related symptoms might commonly affect sleep, and RA-specific pain may be treated with narcotics.

\section{Statistical analysis}

All data were analyzed post hoc and the full analysis set was used, which included all patients who had a valid baseline efficacy measurement and at least one valid post-baseline efficacy measurement. The RAPID3 and CDAI arms were stratified by SCP status. RAPID3/CDAI response at week 12 and the DAS28 (based on erythrocyte sedimentation rate (ESR)) LDA (defined as $\leq 3.2$ ) at week 52, including $95 \%$ confidence intervals (CIs) of the difference in response rates between groups, were analyzed using non-parametric analysis of covariance (ANCOVA) [27-29], with assessment tool (RAPID3 or CDAI) or SCP status (plus SCP or minus SCP) as a factor and baseline DAS28(ESR) score, gender, age, prior anti-TNF use, and duration of RA ( $<2$ or $\geq 2$ years) as covariates. Imputation for missing data was based on non-responder imputation for dichotomous variables, and last observation carried forward (LOCF) for continuous variables.

The safety set consisted of all enrolled patients who received at least one dose of study medication, with treatment-emergent adverse events (AEs) defined as taking place at any time between the first dose and 70 days after the last dose of study drug. All AEs were classified by primary system organ class (SOC), using MedDRA version 15.1. Incidence rates (IRs) were calculated per 100 patient-years (PY), with 95\% CIs. Time at risk was measured from initiation of CZP up to the occurrence of the first serious infectious event (SIE), or the total time at risk for patients without SIEs (up to 70 days after the last study dose or patient withdrawal). All statistical analyses were performed in $\mathrm{SAS}^{\circ}$ software (SAS Institute, Cary, NC, USA), version 9.1 .3 or later.

\section{Results}

\section{Patient characteristics}

The full analysis set included 733 patients, with 368 patients randomized to RAPID3 and 365 patients randomized to the CDAI arm of the study. A total of 313 patients ( $43 \%$ overall; RAPID3, $\mathrm{n}=151$; CDAI, $\mathrm{n}=162$ ) met the SCP classification criteria at study baseline. Of these, 92 patients (29.4\%; RAPID3, $\mathrm{n}=47$; CDAI, $\mathrm{n}=45$ ) met the SCP classification due to concomitant medications only (predominantly use of central acting agents (i.e. baclofen, tizanidine, cyclobenzaprine) or SSRIs); 71 patients (22.7\%; RAPID3, $\mathrm{n}=33$; CDAI, $\mathrm{n}=38$ ) met the phenotype due to medical diagnoses only (predominantly depression). The remaining 150 patients (47.9\%; RAPID3, $\mathrm{n}$ $=71$; CDAI, $\mathrm{n}=79$ ) had both concomitant medications and a medical diagnosis (e.g. SSRIs, plus a diagnosis of depression) (Fig. 1, Additional file 1: Table S1).

Baseline characteristics including CDAI, RAPID3, Patient's Global Assessment of Disease Activity (PtGADA), Multi-Dimensional Health Assessment Questionnaire (MDHAQ) Pain, and physical function scores were relatively comparable between patients with and without the phenotype $(+\mathrm{SCP}$ and $-\mathrm{SCP})$ (Table 1). A similar proportion of $+\mathrm{SCP}$ patients (7.9\%, 12/151 RAPID3 and 7.4\%, 12/162 CDAI assessed) and -SCP patients (10.6\%, 23/217 RAPID3 and $7.4 \%, 15 / 203$ CDAI assessed) were withdrawn from the study by week 12 due to lack of efficacy. However, a larger proportion of $+\mathrm{SCP}$ patients $(16.5 \%$, $34 / 206)$ than - SCP patients $(7.6 \%, 22 / 290)$ were withdrawn after week 12 due to lack of efficacy, a 9\% difference between groups (Additional file 1: Table S2). 


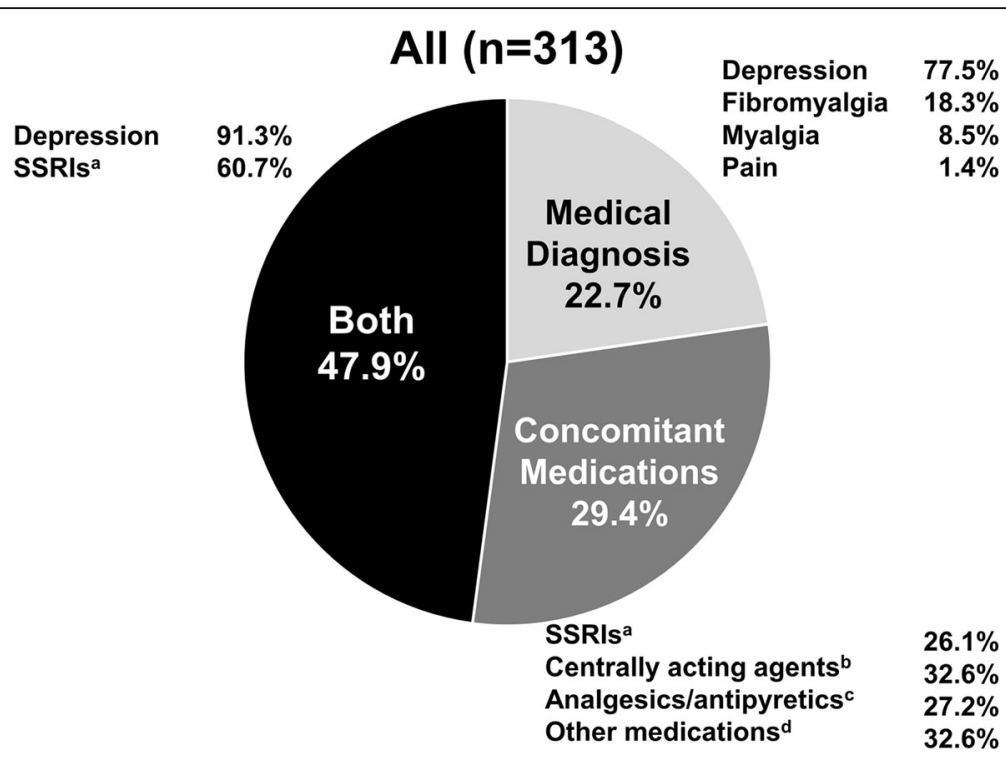

Fig. 1 Proportions of patients meeting criteria for the somatization comorbidity phenotype classification. Full analysis set. The denominator used to calculate the percentage for each category was based upon the total number of patients within the comorbidity/treatment assignment category; the sum of percentages was over 100\% due to some patients taking more than one concomitant medication and/or possessing more than one medical diagnosis. ${ }^{a}$ Defined as Anatomical Therapeutic Chemical Classification System (ATC) code N06AB. ${ }^{b}$ Defined as ATC code M03BX. ${ }^{\mathrm{c}}$ Defined as ATC code N02BG. Included medications in ATC codes N06AA (non-selective monoamine reuptake inhibitors), N06AX (other antidepressants), M03BA (carbamic acid esters), and M03BB (oxazol, thiazine, and triazine derivatives). SSRI selective serotonin reuptake inhibitors

\section{Disease activity control and response at week 12}

The proportion of patients classified as responders at week 12 according to RAPID3 or CDAI definitions was similar, irrespective of SCP status (+SCP 70.6\%, 221/313; -SCP $70.5 \%, 296 / 420$; difference in proportion $0.8 \%$ (95\% CI $-5.9 \%, 7.4 \%)$ ) (Fig. 2a). However, in the CDAI group, the likelihood of being classified as a week-12 responder was incrementally smaller for +SCP patients $(73.5 \%, 119 / 162)$ versus -SCP patients $(78.8 \%, 160 / 203)$ (Fig. 2a). Combining the RAPID3 and CDAI arms, fewer +SCP patients (23.3\%, 73/313) than -SCP patients achieved DAS28(ESR) LDA at week $12(29.0 \%, 122 / 420$; difference in proportion $-4.9 \%$ (95\% CI - 11.0\%, 1.2\%)) (Fig. 2b).

\section{Disease activity control and response at week 52}

At week 52, only half as many + SCP patients (16.0\%, 26/162) in the CDAI assessment group achieved LDA, in comparison with the -SCP patients $(32.0 \%, 65 / 203)$ (Fig. 2c). Similarly, only about half of the + SCP patients $(21.0 \%, 25 / 119)$ in the CDAI assessment group who were week-12 responders achieved LDA at week 52 in comparison to the -SCP patients $(40.6 \%, 65 / 160)$ (Fig. $2 d$ ). In contrast, this phenotype was less differentiating among patients randomized to the RAPID3 assessment arm (Fig. 2c, d). Overall, a smaller proportion of $+\mathrm{SCP}$ patients $(19.2 \%, 60 / 313)$ achieved LDA at week 52 than -SCP patients $(26.2 \%, 110 / 420$; difference in proportion $-6.2 \%$
(95\% CI - 12.2\%, - 0.2\%)) (Fig. 2c). Amongst the week 12 responders, fewer +SCP patients $(25.3 \%, 56 / 221)$ achieved LDA at week 52 in comparison with the $-\mathrm{SCP}$ patients (36.8\%, 109/296; difference in proportion - 10.6\% (95\% CI $-18.4 \%,-2.8 \%-)$ ) (Fig. 2d).

The improvement in mean DAS28(ESR) scores was consistently better in -SCP patients throughout the duration of the study. The difference according to SCP status was most apparent for patients randomized to the CDAI assessment group (Additional file 1: Figure S1). At week 52, the median DAS28(ESR) score for week-12 responders was 3.97 for the $221+\mathrm{SCP}$ patients, versus 3.37 for the $296-$ SCP patients, equivalent to a 0.6-unit difference between presence and absence of the SCP. Similar trends were observed for RAPID3 and CDAI, where +SCP patients reported higher DAS28(ESR) scores (RAPID3 $9.06 \pm 6.19$, CDAI 15.34 \pm 13.07 (mean \pm SD)) than - SCP patients (RAPID3 $6.99 \pm 6.10$, CDAI $11.17 \pm 11.41)$.

Clinical response by achievement of ACR20/50/70

Overall, approximately 5-10\% fewer +SCP patients achieved ACR 20\% response (ACR20), ACR50, and ACR70 throughout the study. At week 52, 44.8\% (188/420), 31.7\% $(133 / 420)$, and $21.0 \%(88 / 420)$ of -SCP patients achieved ACR20, ACR50, and ACR70, respectively, versus $35.1 \%$ 
Table 1 Patient baseline characteristics by SCP status ${ }^{\text {a }}$

\begin{tabular}{|c|c|c|}
\hline & $+\mathrm{SCP}(\mathrm{n}=313)$ & $-\operatorname{SCP}(n=420)$ \\
\hline \multicolumn{3}{|l|}{$\begin{array}{l}\text { Mean (SD), } n \text { unless otherwise } \\
\text { stated }\end{array}$} \\
\hline \multicolumn{3}{|l|}{ Randomized to assessment arm } \\
\hline RAPID3, $n$ (\% overall) & $151(48.2)$ & $217(51.7)$ \\
\hline CDAl, $n$ (\% overall) & $162(51.8)$ & $203(48.3)$ \\
\hline DAS28(ESR) & $6.34(1.07), 306$ & $6.27(1.07), 411$ \\
\hline DAl & 41.41 (13.25), 307 & $39.30(13.01), 416$ \\
\hline RAPID3 & $16.76(5.31), 308$ & $15.56(5.73), 415$ \\
\hline TJC & $16.82(6.81), 308$ & $15.08(6.74), 416$ \\
\hline SJC & $12.12(5.65), 308$ & $12.26(5.66), 416$ \\
\hline $\operatorname{PhGADA}(\mathrm{VAS})^{\mathrm{b}}$ & 6.19 (1.83), 308 & $6.21(1.78), 416$ \\
\hline PtGADA $(\text { VAS })^{b}$ & $6.21(2.23), 308$ & $5.74(2.35), 416$ \\
\hline Pain MDHAQ-PN (0-10 scale) & $6.83(2.07), 308$ & $6.33(2.16), 415$ \\
\hline $\begin{array}{l}\text { Physical function MDHAQ-FN } \\
\text { (converted to 0-10 scale } \\
\text { for RAPID3) }\end{array}$ & $3.73(1.82), 308$ & $3.49(1.92), 416$ \\
\hline \multicolumn{3}{|c|}{$\begin{array}{l}\text { Full analysis set of the PREDICT trial. For these baseline values, some patients } \\
\text { ( }<3 \% \text { overall) were excluded due to prohibited concomitant medications } \\
\text { affecting their assessments. Those with valid assessments at subsequent study } \\
\text { visits were not excluded from the overall study } \\
\text { Abbreviations: SCP somatization comorbidity phenotype, ESR erythrocyte } \\
\text { sedimentation rate, CDAI Clinical Disease Activity Index, DAS28 Disease Activity } \\
\text { Score in } 28 \text { joints, MDHAQ Multidimensional Health Assessment Questionnaire, } \\
\text { PhGADA Physician's Global Assessment of Disease Activity, PtGADA Patient's } \\
\text { Global Assessment of Disease Activity, RAPID3 Routine Assessment of Patient } \\
\text { Index Data 3, SJC swollen joint count, TJC tender joint count } \\
\text { a'Combining the RAPID3 and CDAl arms } \\
\text { bVisual analog scale (0-100 mm converted to cm) }\end{array}$} \\
\hline
\end{tabular}

(110/313), 25.2\% (79/313), and 16.6\% (52/313) of +SCP patients (Fig. 3a-c).

This trend was particularly noticeable in the group assessed by CDAI, with $46.8 \%$ (95/203), 34.0\% (69/203), and $23.6 \%(48 / 203)$ of $-\mathrm{SCP}$ patients versus $32.7 \%$ (53/162), $22.2 \%(36 / 162)$, and $13.6 \%(22 / 162)$ of + SCP patients achieving ACR20, ACR50, and ACR70, respectively, at week 52 . These results indicate an approximate 10-14\% lower ACR clinical response in +SCP patients (Fig. 4a-c). Smaller differences in ACR20, ACR50, and ACR70 response rates were observed for those patients randomized to RAPID3 (Fig. 4a-c).

\section{Safety results}

The safety set comprised a total of 736 patients. Overall, the cumulative one-year incidence of treatment-emergent adverse events (TEAEs) was higher in +SCP patients (82.5\%, 259/314) versus -SCP patients $(71.1 \%, 300 / 422)$, with an incidence rate (IR) of 351.3/100 PY for +SCP patients versus 201.9/100 PY for -SCP patients. In particular, the incidence of infections and infestations was higher in +SCP patients compared to -SCP patients (108.6/100 PY versus 56.0/100 PY) (Table 2). Similarly, the IR of serious infectious events (SIEs) was also higher in +SCP patients compared with -SCP patients (5.0/100 PY versus 1.7/100 PY, a difference of 3.3/100 PY). The number of study discontinuations due to AEs was similar among $+\mathrm{SCP}$ and -SCP patients.

\section{Discussion}

In this large RA population with moderate to severe, active RA, we have described a method to efficiently identify a potentially important patient phenotype in a clinical trial setting that includes depression, anxiety, and chronic pain syndromes such as fibromyalgia and neuropathic pain. Patients enrolled in the PREDICT study were assigned to this phenotype based on concomitant medications and/or medical diagnosis at baseline. In total, $43 \%$ of patients met the SCP classification at study baseline, and patients with this phenotype demonstrated a substantially lower likelihood of treatment response.

In particular, the SCP that we have defined appears to be important with respect to both predicting treatment response at week 12 (23.3\% of + SCP patients achieved DAS28(ESR) LDA versus $29.0 \%$ of -SCP patients) and the likelihood of achieving an LDA state after one year of treatment with CZP (25.3\% of +SCP patients versus $36.8 \%$ of $-\mathrm{SCP}$ patients). Furthermore, +SCP patients were $5-14 \%$ less likely to achieve ACR20, ACR50, and ACR70 throughout the duration of the 52-week study. Those with the SCP were also 9\% more likely to withdraw over the course of this one-year trial. Although speculative, this higher rate of withdrawal for patients with the SCP could be due to perceived lack of benefit of CZP, lower adherence, a higher rate of some AEs, or other factors.

Overall, when using CDAI as the assessment tool, patients with the SCP appeared less likely to be classified as treatment responders by week 12 . Response rates appeared to be more comparable regardless of SCP status when the RAPID3 tool was used. This may reflect the fact that CDAI and the DAS28(ESR) - the primary outcome used in the PREDICT trial - are more highly correlated with each other than the RAPID3 and the DAS28(ESR) [30-32].

Our results may have implications for routine clinical care in deciding which tool to use for RA assessment, given that the RAPID3 reflects a more patient-centric and arguably more holistic assessment than the CDAI, and it is also likely to be easier to implement in busy practices [33]. Irrespective of the SCP phenotype, the primary results of the PREDICT trial showed some differences between the CDAI versus the RAPID3 in the proportion of people classified as responders at 12 weeks [15]. Ultimately, the choice of the preferred tool to assess RA disease activity and treatment response for patients both with and without the SCP phenotype must balance multiple considerations related 


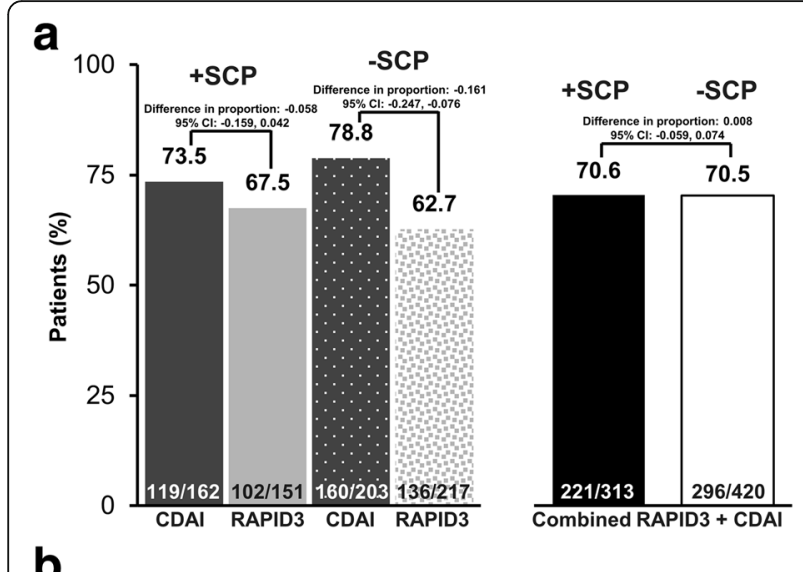

b


Fig. 2 Clinical response by assessment tool and presence of somatization comorbidity phenotype (SCP). a Proportion of Routine Assessment of Patient Index Data 3 (RAPID3) and Clinical Disease Activity Index (CDAl) responders ${ }^{a}$ at week 12 . b Proportion of patients assigned to RAPID3 and CDAI with Disease Activity Score in 28 joints based on erythrocyte sedimentation rate (DAS28(ESR)) low disease activity (LDA) at week 12. c Proportion of patients with DAS28(ESR) LDA at week 52. d Proportion of RAPID3 and CDAI week 12 responders ${ }^{\mathrm{a}}$ with $\mathrm{DAS} 28(\mathrm{ESR}) \mathrm{LDA}$ at week 52 . Full analysis set.

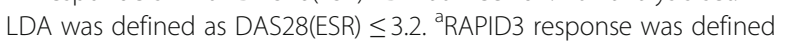
as $\leq 6$ or $20 \%$ improvement from baseline, and CDAl response was defined by $\leq 10$ or $20 \%$ improvement from baseline. Missing data were handled by non-responder imputation

to performance, feasibility, and the relative importance of physician versus patient data.

The results of our study align with data from previous reports, which demonstrate that depression, anxiety, fibromyalgia, and neuropathic pain are prevalent comorbidities in patients with RA and are associated with increased disease activity, poor treatment adherence, and a reduced likelihood of achieving LDA or remission $[2,6,7,24,34,35]$. Ours is among the first to quantify the impact on a large RA clinical trial patient population with active disease starting treatment with a therapeutic agent known to be effective based on the results of previous phase 3 studies. These differences extended not only to the clinical efficacy outcomes, but also to safety endpoints. The incident rate of TEAEs was higher in +SCP patients than in -SCP patients, with a notably higher rate of infectious events in the +SCP group, including SIEs. The magnitude of the difference in the rates of SIEs between + SCP and -SCP patients (3.3/100 PY) in this analysis, all of whom were receiving CZP therapy, was comparable to the difference between CZP and placebo treatment in other RA studies [36]. Depression and other patient factors have been associated with adverse events such as infections [37], cardiovascular disease [38], myocardial infarction [39], and an increased risk of mortality [40], according to past studies. This may reflect a true biologic association, as inflammatory markers such as $\mathrm{C}$-reactive protein have been shown to be associated with depression [41], although these conditions may be a proxy for related factors (e.g. health-seeking behavior, perceived illness severity) that could impact the reporting of more subjective or less severe adverse events. Collectively, these findings suggest that the SCP phenotype may be a useful and easily ascertained proxy in an RA clinical trial population for factors making patients less likely to achieve a good clinical response and less likely to tolerate some RA treatments.

The limitations of these analyses included the fact that the PREDICT study only enrolled patients in the USA, and the patients with fibromyalgia symptomatic enough 


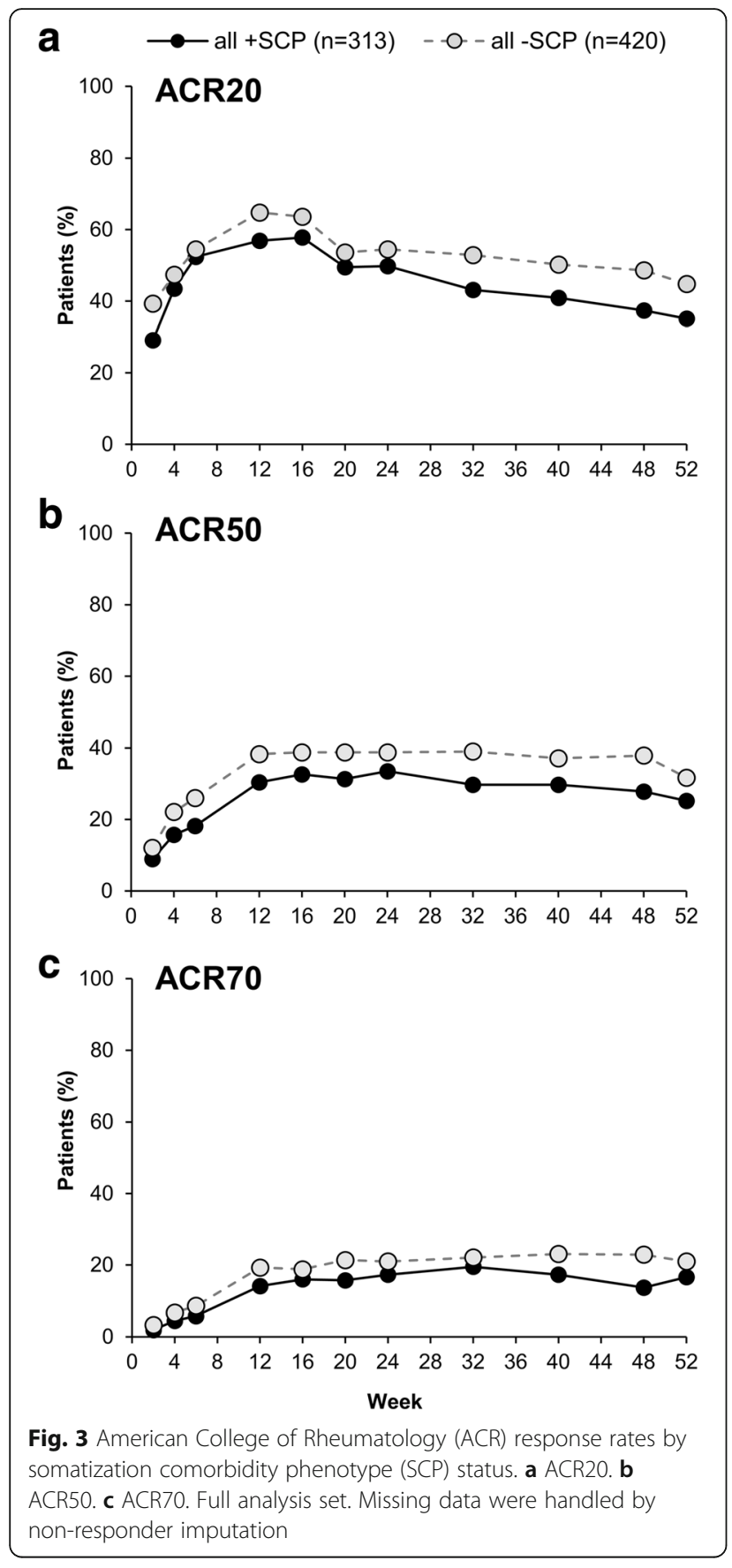

to be treated were excluded by protocol at the discretion of the local investigator, though no systematic identification or exclusion at the time of randomization was enforced. In addition, it is possible that patients with the SCP but who did not have a formal diagnosis and who were not taking any indicated medications, were misclassified. Assuming that the patients with the most severe manifestations of this condition were excluded from the study, and that some patients had not been diagnosed nor were using medication to manage their

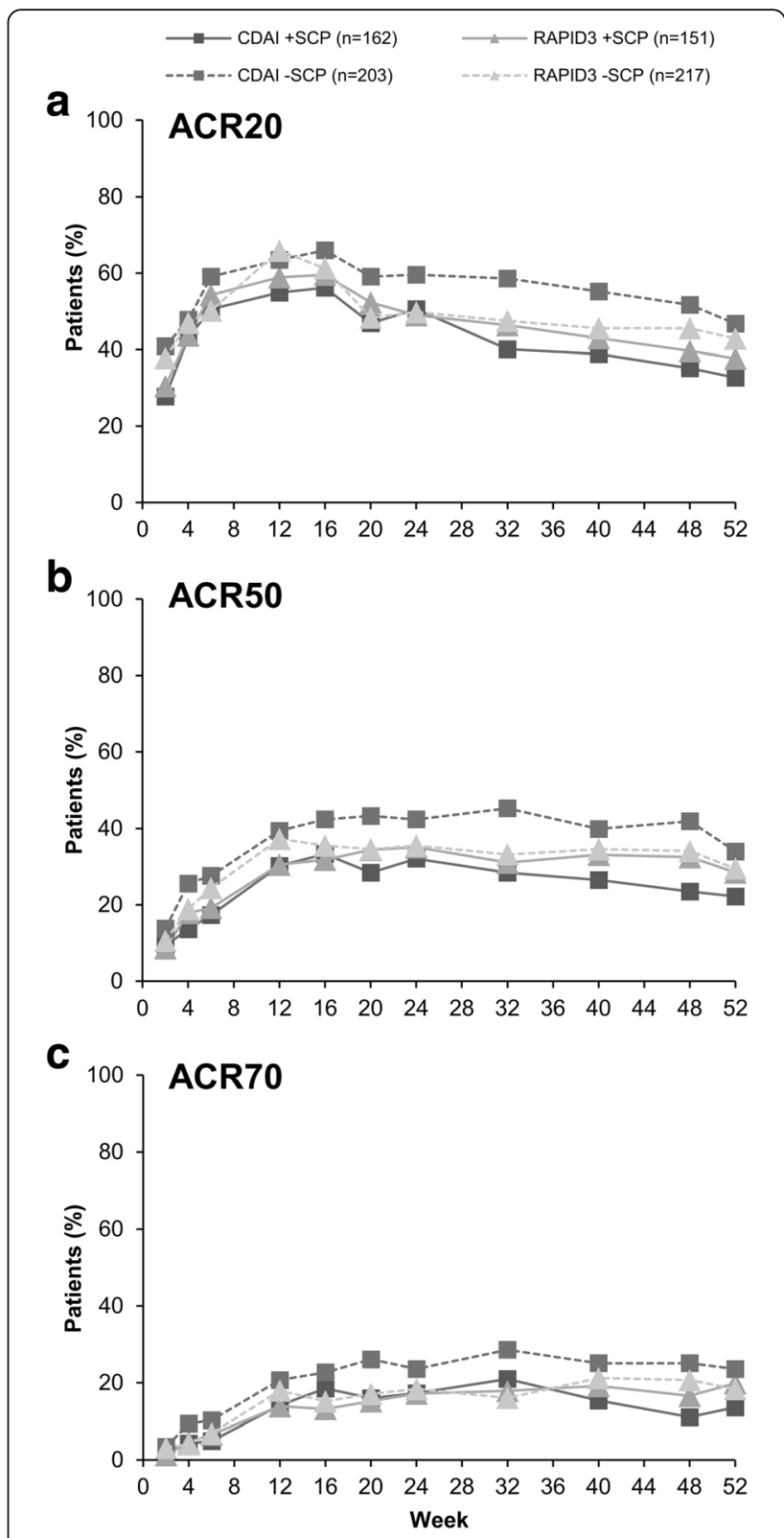

Fig. 4 American College of Rheumatology (ACR) response rates by assessment group and somatization comorbidity phenotype (SCP) status. a ACR20. b ACR50. c ACR70. Full analysis set. Missing data were handled by non-responder imputation

SCP, our results likely represent a conservative estimate of the effect that the SCP phenotype had on treatment response as measured by standard tools such as the achievement of DAS28(ESR) LDA and ACR response, suggesting that the impact of this phenotype in realworld settings may be even more profound. This exclusion might raise concerns about the generalizability of the study's results to the typical RA patient population seen in the USA. However, even with the exclusion in place, we note that a high proportion of patients using 
Table 2 Summary of adverse events by SCP status ${ }^{a}$

\begin{tabular}{|c|c|c|c|}
\hline $\begin{array}{l}\text { Number (percentage), incidence ratio }(95 \% \mathrm{Cl})^{\mathrm{b}} \text {, } \\
\text { unless otherwise indicated }\end{array}$ & $+\operatorname{SCP}(n=314)$ & $-\operatorname{SCP}(n=422)$ & All patients $(n=736)$ \\
\hline Total time at risk (100 PY) & 2.44 & 3.49 & 5.92 \\
\hline Any TEAEs & 259 (82.5), $351.3(309.8,396.8)$ & 300 (71.1), $201.9(179.7,226.1)$ & 559 (76.0), $251.4(231.0,273.2)$ \\
\hline \multicolumn{4}{|l|}{ TEAEs $\left(\geq 5 \%\right.$ in any $\left.\mathrm{SOC}^{\mathrm{c}}\right)$} \\
\hline Gastrointestinal disorders & $65(20.7), 31.3(24.2,39.9)$ & $73(17.3), 24.0(18.8,30.2)$ & $138(18.8), 26.9(22.6,31.8)$ \\
\hline $\begin{array}{l}\text { General disorders and administration } \\
\text { site conditions }\end{array}$ & $48(15.3), 22.5(16.6,29.8)$ & $53(12.6), 17.1(12.8,22.3)$ & $101(13.7), 19.3(15.7,23.4)$ \\
\hline Infections and infestations & 166 (52.9), $108.6(92.7,126.4)$ & $144(34.1), 56.0(47.2,65.9)$ & $310(42.1), 75.6(67.4,84.5)$ \\
\hline $\begin{array}{l}\text { Injury, poisoning, and procedural } \\
\text { complications }\end{array}$ & $41(13.1), 18.6(13.4,25.3)$ & $34(8.1), 10.2(7.1,14.3)$ & $75(10.2), 13.6(10.7,17.0)$ \\
\hline Investigations & $39(12.4), 17.6(12.5,24.1)$ & $50(11.8), 15.8(11.7,20.8)$ & $89(12.1), 16.5(13.3,20.4)$ \\
\hline Metabolism and nutrition disorders & $21(6.7), 9.1(5.6,13.9)$ & $22(5.2), 6.6(4.1,9.9)$ & $43(5.8), 7.6(5.5,10.2)$ \\
\hline $\begin{array}{l}\text { Musculoskeletal and connective tissue } \\
\text { disorders }\end{array}$ & $100(31.8), 52.5(42.7,63.9)$ & $80(19.0), 26.0(20.6,32.4)$ & $180(24.5), 36.2(31.1,41.8)$ \\
\hline Nervous system disorders & $59(18.8), 28.5(21.7,36.8)$ & $34(8.1), 10.3(7.1,14.3)$ & $93(12.6), 17.3(14.0,21.2)$ \\
\hline Psychiatric disorders & $29(9.2), 12.8(8.5,18.3)$ & $10(2.4), 2.9(1.4,5.4)$ & $39(5.3), 6.9(4.9,9.4)$ \\
\hline $\begin{array}{l}\text { Respiratory, thoracic, and mediastinal } \\
\text { disorders }\end{array}$ & $48(15.3), 22.4(16.5,29.7)$ & $48(11.4), 14.9(11.0,19.8)$ & $96(13.0), 17.9(14.5,21.9)$ \\
\hline $\begin{array}{l}\text { Skin and subcutaneous tissue } \\
\text { disorders }\end{array}$ & $44(14.0), 20.1(14.6,27.0)$ & $50(11.8), 15.5(11.5,20.5)$ & $94(12.8), 17.4(14.0,21.3)$ \\
\hline Vascular disorders & $26(8.3), 11.4(7.5,16.8)$ & $17(4.0), 5.0(2.9,8.0)$ & $43(5.8), 7.6(5.5,10.2)$ \\
\hline Serious TEAEs & $34(10.8), 14.8(10.3,20.7)$ & $37(8.8), 10.9(7.7,15.0)$ & $71(9.6), 12.5(9.8,15.8)$ \\
\hline Serious infections and infestations & $12(3.8), 5.0(2.6,8.7)$ & $6(1.4), 1.7(0.6,3.8)$ & $18(2.4), 3.1(1.8,4.8)$ \\
\hline Discontinuation due to TEAEs ${ }^{\mathrm{d}}$ & 34 (10.8), NA & 44 (10.4), NA & 78 (10.6), NA \\
\hline Drug-related TEAEs & 80 (25.5), NA & 93 (22.0), NA & 173 (23.5), NA \\
\hline Severe TEAEs & 38 (12.1), NA & $38(9.0), \mathrm{NA}$ & 76 (10.3), NA \\
\hline Deaths (TEAEs leading to death) & $1(0.3), \mathrm{NA}$ & $1(0.2), \mathrm{NA}$ & $2(0.3), N A$ \\
\hline
\end{tabular}

medications indicated for depression, anxiety, neuropathic pain, and fibromyalgia were in fact enrolled in the study and had the SCP (43\% of the PREDICT trial population). Moreover, in many other RA trials, study criteria commonly exclude patients with conditions deemed by the site investigator "to be symptomatic enough to interfere with the measurement of treatment response" $[19,42]$. However, this exclusion criterion is highly subjective and is rarely enforced in a reproducible fashion. For this reason, RA trials can be expected to include a mix of these patients, but previously these individuals have not been easily identified without the added burden of incorporating additional, specific screening tools to classify patients as having fibromyalgia [43] or depression [44]. While these types of screening instruments could be systematically applied to an RA cohort or trial [45], the phenotype we defined has the advantage that it can be applied to data routinely captured at baseline in RA clinical trials, requiring only concomitant medications and/or diagnoses instead of a specific screening instrument, thereby minimizing participant burden for additional data collection.

These analyses have highlighted that the inclusion of large numbers of patients with the phenotype in an RA trial may appreciably affect the proportion of patients who are able to achieve an absolute disease state treatment target, such as LDA or remission. On the other hand, if new trials excluded individuals with the somatization comorbidity phenotype from a trial, this could somewhat limit the generalizability of the results and hinder comparability between trials, as the proportion of such patients in RA trials across the globe is likely to vary widely. In addition, allowing patients with the somatization comorbidity phenotype in RA studies 
may contribute to a ceiling effect, as patients may not demonstrate as much improvement with effective RA therapies in comparison to patients without this phenotype.

\section{Conclusions}

In the PREDICT clinical trial, $43 \%$ of patients met the "somatization comorbidity phenotype" classification criteria for diagnosis and/or use of medications indicated for depression, fibromyalgia, anxiety, or neuropathic pain. These patients were significantly more likely to withdraw from the trial and/or experience adverse events, and approximately $10-14 \%$ less likely to achieve a clinical response. These results suggest that depending on the outcome measure used (e.g. DAS28), enrolling large numbers of patients with this phenotype may affect the proportion able to achieve LDA or remission, making it advisable to consider whether to include, identify, or stratify these patients during the study design or study screening processes in future RA clinical trials.

\section{Additional file}

Additional file 1:Table S1. SCP categories and medical history/ diagnoses at baseline, with missing data handled by non-responder imputation (NRI). Table S2. Patients withdrawn from the study at/before and after week 12 due to lack of efficacy. Figure S1. Mean DAS28(ESR) score by SCP status, with missing data handled by last observation carried forward (LOCF). Full analysis set. (DOCX 1302 kb)

\section{Abbreviations \\ ACR: American College of Rheumatology; AE: Adverse event; ANCOVA: Analysis of covariance; CDAl: Clinical Disease Activity Index; Cl: Confidence interval; CZP: Certolizumab pegol; DAS: Disease activity score; DMARD: Disease-modifying anti-rheumatic drug; ESR: Erythrocyte sedimentation rate; IR: Incidence rate; IXRS: Interactive voice/web-based response system; LDA: Low disease activity; LOCF: Last observation carried forward; MCID: Minimal clinically important difference; MDHAQ: Multi- Dimensional Health Assessment Questionnaire; MedDRA: Medical Dictionary for Regulatory Activities; NMSC: Non-melanoma skin cancer; PhGADA: Physician's Global Assessment of Disease Activity; PtGADA: Patient's Global Assessment of Disease Activity; PY: Patient years; Q2W: Every 2 weeks; RA: Rheumatoid arthritis; RAPID3: Routine Assessment of Patient Index Data 3; SCP: Somatization comorbidity phenotype; SD: Standard deviation; SIE: Serious infectious event; SJC: Swollen joint count; SOC: System organ class; SSRIs: Selective serotonin reuptake inhibitors; TEAE: Treatment- emergent adverse event; TNF: Tumor necrosis factor}

\section{Acknowledgements}

We thank the patients and their caregivers in addition to the investigators and their teams who contributed to this study. The authors acknowledge Lisa Wulund, PhD, of Costello Medical Consulting Ltd (Cambridge, UK), for medical writing and editorial assistance in preparing this manuscript for publication based on the authors' input and direction. All costs associated with the development of this manuscript were funded by UCB Pharma.

\section{Funding}

UCB Pharma sponsored the study and the development of this publication In addition to critically revising the manuscript/publication for important intellectual content, the authors approved the final version to be published. UCB Pharma performed a full review to ensure that the data presented in the publication are scientifically, technically and medically supportable, and in compliance with the intellectual property rights of UCB Pharma. Furthermore, UCB Pharma ensured that the publication complies with applicable laws, regulations, guidelines, and good industry practice.

\section{Availability of data and materials}

The datasets generated and analyzed during this study are available in anonymized format upon reasonable request via the CSDR platform (http://www.clinicalstudydatarequest.com).

\section{Authors' contributions}

JRC, CH, MNN, COB, and YY made substantial contributions to study conception/design, and/or acquisition/analysis/interpretation of data. JRC, $\mathrm{CH}, \mathrm{MNN}, \mathrm{COB}$, and $\mathrm{YY}$ were involved in drafting of the publication, and revising it critically for important intellectual content. JRC, CH, MNN, COB, and $Y Y$ gave final approval of the publication. All authors read and approved the final manuscript.

\section{Ethics approval and consent to participate}

The study protocol, amendments, and patient informed consent were reviewed by a national, regional, or Independent Ethics Committee (IEC) or Institutional Review Board (IRB). Patient informed consent was conducted in accordance with the current version of the applicable regulatory and International Conference on Harmonization ( $\mathrm{ICH}$ ) Good Clinical Practice (GCP) requirements, the ethical principles that have their origin in the principles of the Declaration of Helsinki, and the local laws of the countries involved.

\section{Consent for publication}

Not applicable.

\section{Competing interests}

JRC: research grants and consulting fees from UCB Pharma, Janssen, CORRONA, Amgen, Pfizer, Bristol-Myers Squibb, Crescendo Bioscience. CH: Medical Director at Mylan, former employee of UCB Pharma. MNN: employee of UCB Pharma. COB: employee of UCB Pharma. YY: research grants from Bristol-Myers Squibb, Genentech, Celgene; consulting fees from Bristol-Myers Squibb, Celgene, Samumed.

\section{Publisher's Note}

Springer Nature remains neutral with regard to jurisdictional claims in published maps and institutional affiliations.

\section{Author details}

${ }^{1}$ Division of Clinical Immunology and Rheumatology, University of Alabama at Birmingham, FOT 802, 510 20th Street South, Birmingham, AL 35294, USA. ${ }^{2}$ Mylan, 1000 Mylan Blvd, Canonsburg, PA 15317, USA. ${ }^{3}$ UCB Pharma, Allée de la Recherche 60, 1070 Brussels, Belgium. ${ }^{4} \mathrm{NYU}$ Hospital for Joint Diseases, New York University School of Medicine, 301 East 17th Street, New York, NY 10003, USA

Received: 9 May 2017 Accepted: 29 August 2017

Published online: 29 September 2017

\section{References}

1. Roubille C, Richer V, Starnino T, McCourt C, McFarlane A, Fleming P, Siu S, Kraft J, Lynde C, Pope J, et al. Evidence-based recommendations for the management of comorbidities in rheumatoid arthritis, psoriasis, and psoriatic arthritis: expert opinion of the Canadian DermatologyRheumatology Comorbidity Initiative. J Rheumatol. 2015;42(10):1767-80.

2. Radner H, Yoshida K, Frits M, lannaccone C, Shadick NA, Weinblatt M, Smolen JS, Solomon $\mathrm{DH}$. The impact of multimorbidity status on treatment response in rheumatoid arthritis patients initiating disease-modifying antirheumatic drugs. Rheumatology (Oxford, England). 2015;54(11):2076-84.

3. Theis KA, Brady TJ, Helmick CG. No one dies of old age anymore: a coordinated approach to comorbidities and the rheumatic diseases. Arthritis Care Res. 2017;69(1):1-4

4. Simoes D, Araujo FA, Severo M, Monjardino T, Cruz I, Carmona L, Lucas R. Patterns and consequences of multimorbidity in the general population: there is no chronic disease management without rheumatic disease management. Arthritis Care Res. 2017;69(1):12-20.

5. Murphy LB, Sacks JJ, Brady TJ, Hootman JM, Chapman DP. Anxiety and depression among US adults with arthritis: prevalence and correlates. Arthritis Care Res. 2012;64(7):968-76.

6. Lage-Hansen PR, Chrysidis S, Lage-Hansen M, Hougaard A, Ejstrup L, Amris K. Concomitant fibromyalgia in rheumatoid arthritis is associated with the more 
frequent use of biological therapy: a cross-sectional study. Scand J Rheumat. 2015:45(1):45-8.

7. Matcham F, Norton S, Scott DL, Steer S, Hotopf M. Symptoms of depression and anxiety predict treatment response and long-term physical health outcomes in rheumatoid arthritis: secondary analysis of a randomized controlled trial. Rheumatology (Oxford, England). 2016;55(2):268-78.

8. Overman CL, Kool MB, Da Silva JA, Geenen R. The prevalence of severe fatigue in rheumatic diseases: an international study. Clin Rheumatol. 2016;35(2):409-15.

9. Anderson J, Caplan L, Yazdany J, Robbins ML, Neogi T, Michaud K, Saag KG, O'Dell JR, Kazi S. Rheumatoid arthritis disease activity measures: American College of Rheumatology recommendations for use in clinical practice. Arthritis Care Res. 2012;64(5):640-7.

10. Castrejon I, Pincus T. Patient self-report outcomes to guide a treat-to-target strategy in clinical trials and usual clinical care of rheumatoid arthritis. Clin Exp Rheumatol. 2012;30(4 Suppl 73):S50-55.

11. Pincus T, Swearingen CJ, Bergman M, Yazici Y. RAPID3 (Routine Assessment of Patient Index Data 3), a rheumatoid arthritis index without formal joint counts for routine care: proposed severity categories compared to disease activity score and clinical disease activity index categories. J Rheumatol. 2008;35(11):2136-47.

12. Sokka T, Hetland ML, Makinen $H$, Kautiainen $H$, Horslev-Petersen $\mathrm{K}$, Luukkainen RK, Combe B, Badsha H, Drosos AA, Devlin J, et al. Remission and rheumatoid arthritis: data on patients receiving usual care in twentyfour countries. Arthritis Rheum. 2008;58(9):2642-51.

13. Saag KG, Teng GG, Patkar NM, Anuntiyo J, Finney C, Curtis JR, Paulus HE, Mudano A, Pisu M, Elkins-Melton M, et al. American College of Rheumatology 2008 recommendations for the use of nonbiologic and biologic disease-modifying antirheumatic drugs in rheumatoid arthritis. Arthritis Rheum. 2008;59(6):762-84.

14. Smolen JS, Boers M, Abadie EC, Breedveld FC, Emery P, Bardin T, Goel N, Ethgen DJ, Avouac BP, Dere WH, et al. Recommendations for an update of 2003 European regulatory requirements for registration of drugs to be used in the treatment of RA. Curr Med Res Opin. 2011;27(2):315-25.

15. Curtis JR, Churchill M, Kivitz A, Samad A, Gauer L, Gervitz L, Koetse W, Melin J, Yazici Y. A randomized trial comparing disease activity measures to assess and predict response in rheumatoid arthritis patients initiating certolizumab pegol. Arthritis Rheumatol (Hoboken, NJ). 2015;67(12):3104-12.

16. Arnett FC, Edworthy SM, Bloch DA, McShane DJ, Fries JF, Cooper NS, Healey LA, Kaplan SR, Liang MH, Luthra HS, et al. The American Rheumatism Association 1987 revised criteria for the classification of rheumatoid arthritis. Arthritis Rheum. 1988:31(3):315-24.

17. Wolfe F, Michaud K, Busch RE, Katz RS, Rasker JJ, Shahouri SH, Shaver TS, Wang S, Walitt BT, Hauser W. Polysymptomatic distress in patients with rheumatoid arthritis: understanding disproportionate response and its spectrum. Arthritis Care Res. 2014;66(10):1465-71.

18. Pincus T, Castrejón I, Block J, Cook N. Patients with fibromyalgia in general have higher self-report questionnaire scores than patients with rheumatoid arthritis: implications for clinical trials and clinical research. Arthritis Rheumatol. 2016;68(Suppl10):54.

19. Pincus T, Yazici Y, van Vollenhoven R. Why are only $50 \%$ of courses of antitumor necrosis factor agents continued for only 2 years in some settings? Need for long term observations in standard care to complement clinical trials. J Rheumatol. 2006;33(12):2372-5.

20. Curtis JR, Yang S, Chen L, Pope JE, Keystone EC, Haraoui B, Boire G, Thorne JC, Tin $D$, Hitchon $C A$, et al. Determining the minimally important difference in the clinical disease activity index for improvement and worsening in early rheumatoid arthritis patients. Arthritis Care Res. 2015;67(10):1345-53.

21. Pincus $T$, Hines $P$, Bergman MJ, Yazici Y, Rosenblatt LC, MacLean R. Proposed severity and response criteria for Routine Assessment of Patient Index Data (RAPID3): results for categories of disease activity and response criteria in abatacept clinical trials. J Rheumatol. 2011;38(12):2565-71.

22. Pincus T, Yazici Y, Bergman MJ. RAPID3, an index to assess and monitor patients with rheumatoid arthritis, without formal joint counts: similar results to DAS28 and CDAl in clinical trials and clinical care. Rheum Dis Clin N Am. 2009;35(4):773-8. viii.

23. Duran J, Combe B, Niu J, Rincheval N, Gaujoux-Viala C, Felson DT. The effect on treatment response of fibromyalgic symptoms in early rheumatoid arthritis patients: results from the ESPOIR cohort. Rheumatology (Oxford, England). 2015;54(12):2166-70.

24. Inanc N, Yilmaz-Oner S, Can M, Sokka T, Direskeneli H. The role of depression, anxiety, fatigue, and fibromyalgia on the evaluation of the remission status in patients with rheumatoid arthritis. J Rheumatol. 2014; 41(9):1755-60.

25. Andersson ML, Svensson B, Bergman S. Chronic widespread pain in patients with rheumatoid arthritis and the relation between pain and disease activity measures over the first 5 years. J Rheumatol. 2013; 40(12):1977-85.

26. Ton E, Bakker MF, Verstappen SM, Ter Borg EJ, van Albada-Kuipers IA, Schenk Y, van der Veen MJ, Bijlsma JW, Jacobs JW. Utrecht Rheumatoid Arthritis Cohort Study Group. Look beyond the disease activity score of 28 joints (DAS28): tender points influence the DAS28 in patients with rheumatoid arthritis. J Rheumatol. 2012;39(1):22-7.

27. Koch GG, Tangen CM, Jung JW, Amara IA. Issues for covariance analysis of dichotomous and ordered categorical data from randomized clinical trials and non-parametric strategies for addressing them. Stat Med. 1998;17(15-16):1863-92.

28. LaVange LM, Durham TA, Koch GG. Randomization-based nonparametric methods for the analysis of multicentre trials. Stat Methods Med Res. 2005;14(3):281-301.

29. Zink RC, Koch GG. SAS ${ }^{\oplus}$ Macro NParCov Version 2, Non-parametric analysis of covariance user's guide. 2002.

30. Aletaha D, Nell VP, Stamm T, Uffmann M, Pflugbeil S, Machold K, Smolen JS. Acute phase reactants add little to composite disease activity indices for rheumatoid arthritis: validation of a clinical activity score. Arthritis Res Ther. 2005;7(4):R796-806.

31. Pincus T, Furer V, Keystone E, Yazici Y, Bergman MJ, Luijtens K. RAPID3 (Routine Assessment of Patient Index Data 3) severity categories and response criteria: Similar results to DAS28 (Disease Activity Score) and CDAI (Clinical Disease Activity Index) in the RAPID 1 (Rheumatoid Arthritis Prevention of Structural Damage) clinical trial of certolizumab pegol. Arthritis Care Res. 2011;63(8):1142-9.

32. Pincus T. Can RAPID3, an index without formal joint counts or laboratory tests, serve to guide rheumatologists in tight control of rheumatoid arthritis in usual clinical care? Bull NYU Hosp Jt Dis. 2009;67(3):254-66

33. Berthelot J-M. RAPID3? Aptly named! Clin Exp Rheumatol. 2014;32 (Suppl 85):S80-84.

34. Wolfe F, Michaud K. Severe rheumatoid arthritis (RA), worse outcomes, comorbid illness, and sociodemographic disadvantage characterize RA patients with fibromyalgia. J Rheumatol. 2004;31(4):695-700.

35. Toms J, Soukup T, Bradna P, Hrncir Z. Disease activity composite indices in patients with rheumatoid arthritis and concomitant fibromyalgia. J Rheumatol. 2010;37(2):468. Author reply 469.

36. Bykerk VP, Cush J, Winthrop K, Calabrese L, Lortholary O, de Longueville M, van Vollenhoven $\mathrm{R}$, Mariette X. Update on the safety profile of certolizumab pegol in rheumatoid arthritis: an integrated analysis from clinical trials. Ann Rheum Dis. 2015;74(1):96-103.

37. Kunutsor SK, Whitehouse MR, Blom AW, Beswick AD, Team I. Patient-related risk factors for periprosthetic joint infection after total joint arthroplasty: a systematic review and meta-analysis. PLoS One. 2016;11(3):e0150866.

38. Treharne GJ, Hale ED, Lyons AC, Booth DA, Banks MJ, Erb N, Douglas KM, Mitton DL, Kitas GD. Cardiovascular disease and psychological morbidity among rheumatoid arthritis patients. Rheumatology (Oxford, England). 2005:44(2):241-6.

39. Scherrer JF, Virgo KS, Zeringue A, Bucholz KK, Jacob T, Johnson RG, True WR Carney RM, Freedland KE, Xian $\mathrm{H}$, et al. Depression increases risk of incident myocardial infarction among Veterans Administration patients with rheumatoid arthritis. Gen Hosp Psychiatry. 2009;31(4):353-9.

40. Ang DC, Choi H, Kroenke K, Wolfe F. Comorbid depression is an independent risk factor for mortality in patients with rheumatoid arthritis. J Rheumatol. 2005;32(6):1013-9.

41. Kojima M, Kojima T, Suzuki S, Oguchi T, Oba M, Tsuchiya H, Sugiura F, Kanayama Y, Furukawa TA, Tokudome S, et al. Depression, inflammation, and pain in patients with rheumatoid arthritis. Arthritis Rheum. 2009;61(8): $1018-24$.

42. Pincus T, Sokka T. Should contemporary rheumatoid arthritis clinical trials be more like standard patient care and vice versa? Ann Rheum Dis. 2004; 63(Suppl2):ii32-9.

43. Wolfe F, Clauw DJ, Fitzcharles MA, Goldenberg DL, Katz RS, Mease P, Russell AS, Russell IJ, Winfield JB, Yunus MB. The American College of Rheumatology preliminary diagnostic criteria for fibromyalgia and measurement of symptom severity. Arthritis Care Res. 2010;62(5):600-10. 
44. Kroenke K, Spitzer RL, Williams JB. The PHQ-9: validity of a brief depression severity measure. J Gen Intern Med. 2001;16(9):606-13.

45. Perrot S, Peixoto M, Dieude P, Hachulla E, Avouac J, Ottaviani S, Allanore Y. Patient phenotypes in fibromyalgia comorbid with systemic sclerosis or rheumatoid arthritis: influence of diagnostic and screening tests. Screening with the FiRST questionnaire, diagnosis with the ACR 1990 and revised ACR 2010 criteria. Clin Exp Rheumatol. 2017;35 Suppl 105(3):35-42.

Submit your next manuscript to BioMed Central and we will help you at every step:

- We accept pre-submission inquiries

- Our selector tool helps you to find the most relevant journal

- We provide round the clock customer support

- Convenient online submission

- Thorough peer review

- Inclusion in PubMed and all major indexing services

- Maximum visibility for your research

Submit your manuscript at www.biomedcentral.com/submit 